\title{
Pengelolaan lahan gambut tanpa bakar: Upaya alternatif restorasi pada lahan gambut basah
}

\section{Peatland management without burning: Alternative restoration efforts in (re)wet peatlands}

Haris Gunawan $^{\text {ac }}$, Dian Afriyantiad, Ivan A. Humamª, Fajar C. Nugraha ${ }^{a}$, Rahmawati I. Wetadewi ${ }^{\text {a }}$ Lutfiah Surayah $^{\mathrm{a}}$, Adi Nugroho ${ }^{a}$, Sarjiya Antonius ${ }^{b}$

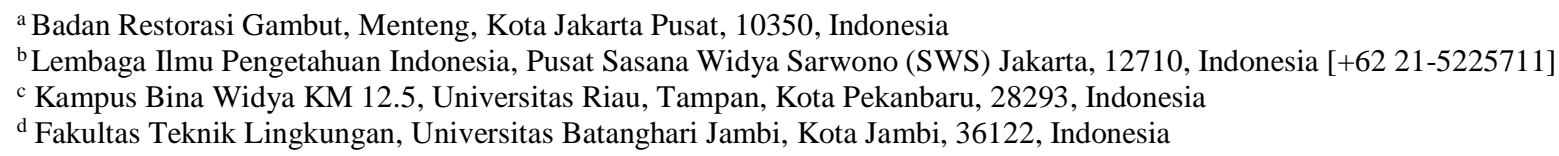

${ }^{\mathrm{d}}$ Fakultas Teknik Lingkungan, Universitas Batanghari Jambi, Kota Jambi, 36122, Indonesia

\section{Article Info:}

Received: 02 - 11 - 2020

Accepted: 20 - 12 - 2020

\section{Keywords:}

Anaerobic, productivity, waterzone, wet peat, without fires

Corresponding Author: Haris Gunawan

Badan Restorasi Gambut, Menteng, Jakarta Pusat;

Email:

haris.gunawan@brg.go.id

\begin{abstract}
In the last two decades, peatland management has resulted in the susceptibility of peatlands to fires due to peat degradation associated with drainages, climate, and culture in opening peatlands. Rewet peatlands are the ultimate goal of peat restoration. Nevertheless, the needs for production in peatlands require a milestone to bridge the measure to restore peatlands hydrologically. Peatland management without fires is a method, and the combination with methods to supply nutrients in wet/moist/anaerobic peatlands would be innovative technology. It is aimed to provide nutrients of organic materials without stimulating the decomposition of peat materials. Along with restoration measure hydrologically, agriculture in cultivation zone of peatlands shall consider water-zone as a specific and small unit within a wide peat hydrological unit.
\end{abstract}

How to cite (CSE Style $8^{\text {th }}$ Edition):

Gunawan H, Afriyanti D, Humam IA, Nugraha FC, Wetadewi RI, Nugroho A, Antonius S. 2020. Pengelolaan lahan gambut tanpa bakar: Upaya alternatif restorasi pada lahan gambut basah. JPSL 10(4): 668-678. http://dx.doi.org/10.29244/jpsl.10.4.668-678.

\section{PENDAHULUAN}

Ekosistem servis dari hutan rawa gambut tropis memberikan manusia manfaat secara ekologi, mitigasi perubahan iklim, manfaat secara sosial-ekonomi, dan penting bagi keanekaragaman hayati (Harrison et al., 2019; Posa et al., 2011). Indonesia sebagai pemilik bentang ekosistem gambut tropis terluas di dunia (BBSDLP, 2011), mengalami degradasi yang sangat mengancam keberlanjutan sumber daya alam ini semasa dua dekade terakhir. Sehingga, kolapsnya ekosistem gambut merupakan ancaman bagi berbagai pihak, terutama masyarakat yang rentan terhadap risiko bencana karena daya mitigasi dan adaptasinya yang rendah. Walaupun secara global, kebakaran lahan gambut adalah penyumbang emisi yang tinggi terutama selama El Niño (Liu et al., 2017), rentannya masyarakat lokal terhadap katastropi degradasi ekosistem gambut ini perlu upaya mitigasi yang inklusif secara sosial dan ekonomi.

Rentannya masyarakat ini dapat digambarkan dari besarnya dampak kebakaran dan kurangnya pengetahuan akan perubahan karakteristik gambut setelah drainase. Kabut asap kebakaran berdampak negatif pada ekonomi, kesehatan hewan, manusia, dan kondisi pohon (Harrison et al., 2016) serta dapat menyebabkan penurunan $\mathrm{pH}$ di sungai gambut yang bersifat asam, sehingga hasil tangkapan ikan dapat menurun (Thornton 
et al., 2018). Kebakaran juga menyebabkan kehilangan permukaan lahan gambut, sehingga mempercepat subsidensi lahan (Hooijer et al., 2012). Sebagai contoh adalah masyarakat Pulau Rangsang, Kabupaten Kepulauan Meranti, Provinsi Riau yang memiliki budaya memerun (membakar dengan dalam skala kecil untuk membersihkan halaman atau kebun). Budaya pertanian memerun yang dahulu ketika gambut masih relatif lebih basah masih aman dilaksanakan. Tetapi, drainase menyebabkan rentannya lahan gambut di Pulau Rangsang mengalami kebakaran ketika drainase sudah luas di lahan gambut semakin kering. Budaya bertani ini praktik tebang-bakar oleh masyarakat untuk kegiatan pembukaan lahan atau persiapan pertanian di lahan gambut merupakan aktivitas yang dominan (Akbar, 2015; Anwar et al., 2010) karena mudah dan murah. Pengelolaan lahan dengan cara dibakar merupakan kegiatan yang telah dilakukan secara turun temurun dan telah menjadi budaya masyarakat karena dianggap sebagai cara yang paling murah dan mudah untuk membersihkan lahan (Yuliani et al., 2019). Penggunaan api sering dipraktikkan oleh perkebunan industri dan masyarakat lokal, khususnya di area yang terdegradasi (Harrison et al., 2016).

Perlindungan dan restorasi terhadap ekosistem gambut menjadi prioritas yang memerlukan tindakan segera (Posa et al., 2011), tetapi pembasahan gambut tidak dapat merestorasi hidrologi gambut secara cepat. Upaya antara diperlukan dalam rangka mencapai tujuan restorasi gambut yang sebenarnya. Lahan gambut masih rentan terhadap risiko kebakaran dengan luasnya kanal yang mengeringkan gambut yang sudah terlanjur dibangun sejak dua dekade terakhir. Upaya pencegahan kebakaran memberikan kesempatan bagi upaya pemulihan ekosistem gambut. Diharapkan gambut yang tersisa dapat dikembalikan fungsinya (Cole et al., 2015). Upaya yang dapat dilakukan adalah mengurangi risiko kebakaran di masa depan dengan pendekatan sosial dalam model produksi pertanian di lahan gambut dangkal. Teknik pembukaan lahan tanpa bakar (PLTB) menjadi salah satu pendekatan untuk mencegah kebakaran hutan dan lahan gambut yang bermanfaat untuk meminimalkan faktor pemicu kebakaran (Hendromono et al., 2007). Khusus untuk lahan gambut, teknik ini juga bisa disebut pengelolaan lahan gambut tanpa bakar (PLGTB). PLGTB diharapkan menjadi salah satu kegiatan yang mendukung upaya pengelolaan lahan gambut yang berkelanjutan (Purnomo dan Puspitaloka, 2020). Penelitian ini bertujuan untuk mendiskusikan pentingnya pengelolaan lahan gambut tanpa bakar secara hidrologi dan inovasi dalam penyediaan unsur hara yang mencegah dekomposisi gambut.

Kebakaran hutan dan lahan merupakan salah satu penyebab utama deforestasi di Indonesia, yang berdampak signifikan terhadap lingkungan, kehilangan konservasi, polusi udara dan kerugian ekonomi (Rezainy et al., 2020). Solusi permasalahan tersebut adalah dengan membuat peraturan yang tegas dan adil untuk mengatasi kebakaran hutan. Pemerintah sebagai regulator dalam pelaksanaan kebijakan ekosistem gambut perlu membuka ruang yang lebih luas untuk perbaikan kebijakan agar seimbang antar aspek pembangunan berkelanjutan, yaitu kelestarian lingkungan, keberlanjutan sosial dan ekonomi (Maulana et al., 2019). Penelitian ini memberikan inovasi dalam pengelolaan lahan gambut tanpa bakar, yang dapat berdampak pada peningkatan produktivitas lahan dan mencegah kebakaran lahan gambut.

\section{METODE}

\section{Lokasi dan Waktu Penelitian}

Penelitian berdasarkan basis data di Kesatuan Hidrologi Gambut Pulau Rangsang, di Kabupaten Kepulauan Meranti. Basis data yang dimaksud adalah data pemantauan tinggi muka air sejak 18 Agustus 2019 hingga 8 Mei 2020. Sedangkan pembuatan agen hayati dilakukan oleh LIPI di Laboratorium Mikrobiologi

LIPI dan pembuatan kompos dilakukan langsung di lokasi penelitian di Siak (Riau) dan Palangka Raya (Kalimantan Tengah) oleh masyarakat yang dipandu oleh LIPI bekerjasama dengan BRG.

\section{Metode Pengumpulan Data}

Pengumpulan data dilaksanakan dengan metode inventori pengukuran tinggi muka air tanah (TMAT) harian dari stasiun pemantauan BRG, data kejadian kebakaran berdasarkan MODIS digunakan untuk pemilihan dua lokasi yang akan dibandingkan antara yang sering terbakar dan cenderung tidak terbakar disertai 
kelengkapan alat pemantau tinggi muka air tanah. Dua titik yang akan dibandingkan berada di pulau Rangsang dengan karakteristik yang disyaratkan. Data TMAT dikumpulkan sejak tahun 2009 sampai dengan 2019 menggunakan data VIRSS dan MODIS serta studi literatur. Data dianalisis secara deskriptif kuantitatif dan kualitatif. Deskriptif kuantitatif dilakukan untuk data-data hidrologi, dan desktiptif kuantitatif dilaksanakan untuk literatur dan praktik-praktik PLTGB.

\section{Metode Analisis Data}

\section{Analisis Hidrologi dan Kejadian Kebakaran}

Analisis hidrologi dilaksanakan dalam rangka mendapatkan dampak gambut terbakar pada semakin tingginya out flow pada neraca air. Dalam analisis ini, dikumpulkan data pengamatan tinggi muka air tanah dan lokasi pemasangan alat. Dari semua wilayah tersebut dipilih satu lokasi yang mencerminkan daerah yang sering terbakar dan tidak, maka Pulau Rangsang yang paling sesuai dengan kondisi tersebut. Kesatuan Hidrologis Gambut (KHG) Pulau Rangsang, di Kabupaten Kepulauan Meranti, Provinsi Riau dipilih sebagai lokasi untuk dianalis TMAT. Pemilihan lokasi ini berdasarkan: (i) ketersediaan data yang dapat menjadi pembeda pengaruh kebakaran, juga masyarakat yang hidup langsung di atas gambut (bukan berada di ecotone atau bagian aluvial lainnya seperti di sebagian besar Sumatera); dan (ii) budaya masyarakat membersihkan halaman dan kebun dengan memerun. Di KHG Pulau Rangsang kebiasaan masyarakat memerun di halaman rumah dan kebun tidak lagi aman sejak terbangunnya kanal-kanal perusahaan (sejak tahun 2003). Analisis dilaksanakan dengan pengamatan data TMA pada dua lokasi yaitu lokasi yang tidak terbakar (BRG-14100301) dan terbakar (BRG_141009-01), dengan data yang tersedia sejak 2019 (Gambar 1). Analisis kejadian kebakaran gambut dilaksanakan berdasarkan pemilihan lokasi yang sering terbakar dan cenderung tidak terbakar. Kemudian kedua lokasi ini dibandingkan berdasarkan fluktuasi muka air tanahnya.

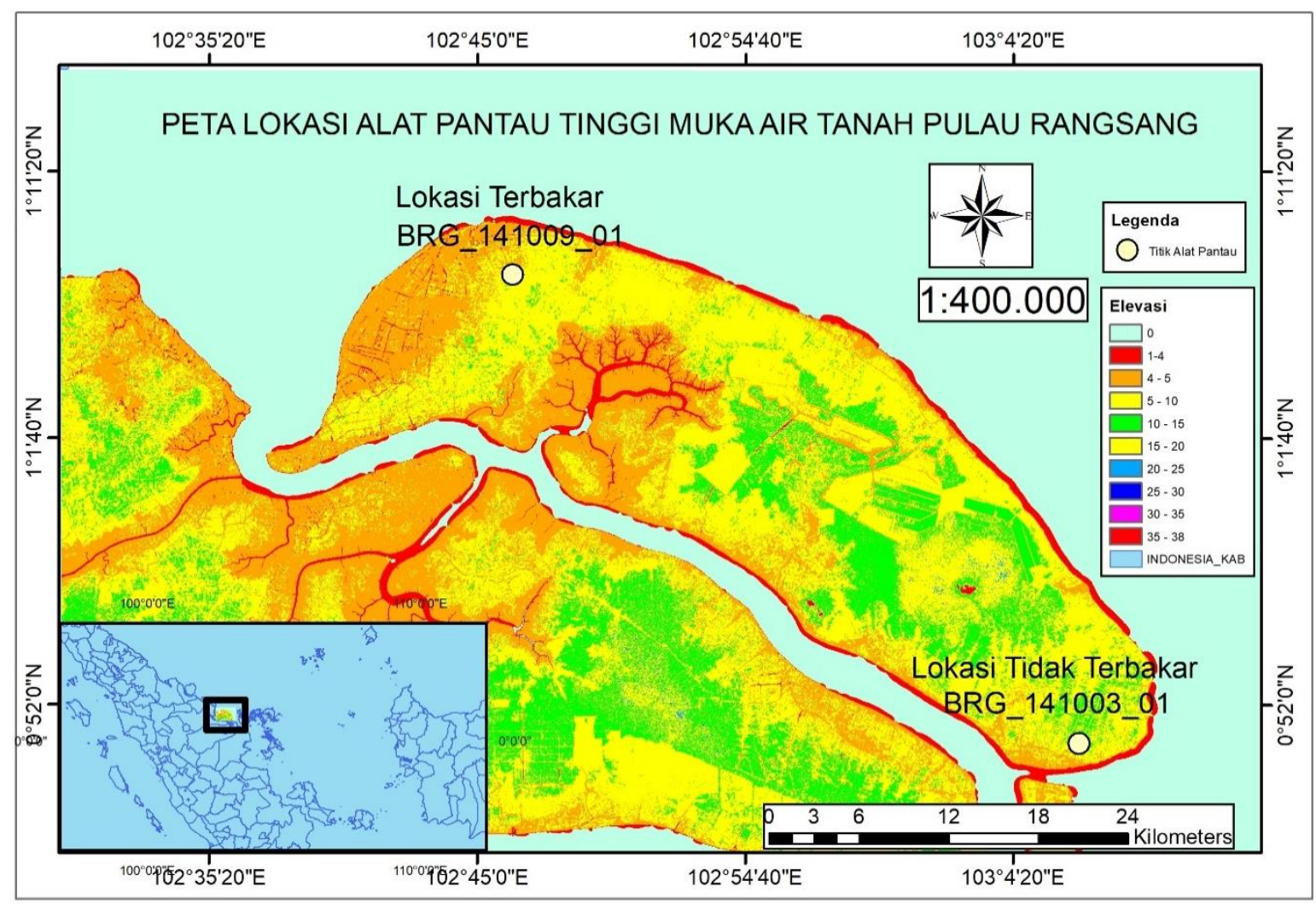

Gambar 1 Peta lokasi alat pantau TMA (Data : Prims.brg.co.id dan tides.big.co.id) 


\section{Studi Inovasi PLTGB}

Paradigma perkembangan ilmu pengetahuan membandingkan kesuburan tanah berdasarkan status kesuburan tanah mineral yang menyebabkan kandungan unsur hara dalam tanah gambut dikategorikan sangat rendah dengan $\mathrm{pH}$ tanah yang sangat asam dan selalu jenuh dengan air sehingga timbul anggapan bahwa gambut adalah lahan yang tidak produktif jika digunakan untuk lahan pertanian dengan konsep tanah mineral. Hal ini memicu konversi lahan gambut dengan sistem drainase untuk menyediakan kondisi yang cocok bagi spesies tanaman yang biasa hidup di lahan kering.

Pada kajian ini, dilakukan tinjauan pada praktik-praktik memperbaiki kesuburan tanah di lahan gambut. Analisis dilakukan pada praktik-praktik ameliorasi di lahan gambut yang dilaksanakan oleh LIPI. Praktik tersebut adalah pengomposan dan penggunaan agen hayati dalam menyediakan unsur hara di lahan gambut. Pengomposan adalah hal yang bisa dilaksanakan dalam pengelolaan lahan marjinal di Indonesia. Tetapi, bagaimana pengomposan ini menjadi inovasi dalam PLTGB adalah hal yang menjadi fokus kajian.

\section{HASIL DAN PEMBAHASAN}

Berdasarkan hasil pengamatan pada data Tinggi Muka Air Tanah (TMAT) dengan menggunakan alat ukur Sipalaga di KHG Pulau Rangsang pada Pembahasana dua lokasi yang berbeda (Gambar 1), yaitu pemilihan lokasi lahan yang sering terbakar dan tidak terbakar menunjukkan perbedaan perilaku fluktuasi muka air tanah. Perbedaan TMA pada dua lokasi disebabkan oleh daya tampung air yang berbeda. Apabila kebakaran terus terjadi maka lahan gambut akan semakin terdegradasi dan daya tampung air akan semakin berkurang. Gambar 2 menunjukkan bahwa kecenderungan lahan yang terbakar memiliki tinggi muka air yang lebih dalam dibandingkan dengan lahan yang cenderung tidak terbakar. Keadaan pada dua titik tersebut memiliki perbedaan yang signifikan dalam tinggi muka air tanah. Kemampuan tanah dalam menyerap dan menahan air akan berkurang berdasarkan deskripsi dari visualisasi hubungan TMAT dengan waktu dari dua lokasi yang berbeda karakteristiknya.

Dua lokasi tersebut menunjukkan bahwa adanya perbedaan fluktuasi TMAT (Gambar 2); dan data hotspot tahun 2009 sampai dengan 2019 menunjukkan pada lokasi terbakar terdapat perbedaan pada satu titik dengan radius $1 \mathrm{KM}$ mengalami kebakaran lebih dari 20 kali, sedangkan pada lokasi yang tidak terbakar sudah tidak pernah ada aktivitas kebakaran selama kurun waktu kurang lebih 10 tahun (Gambar 3).

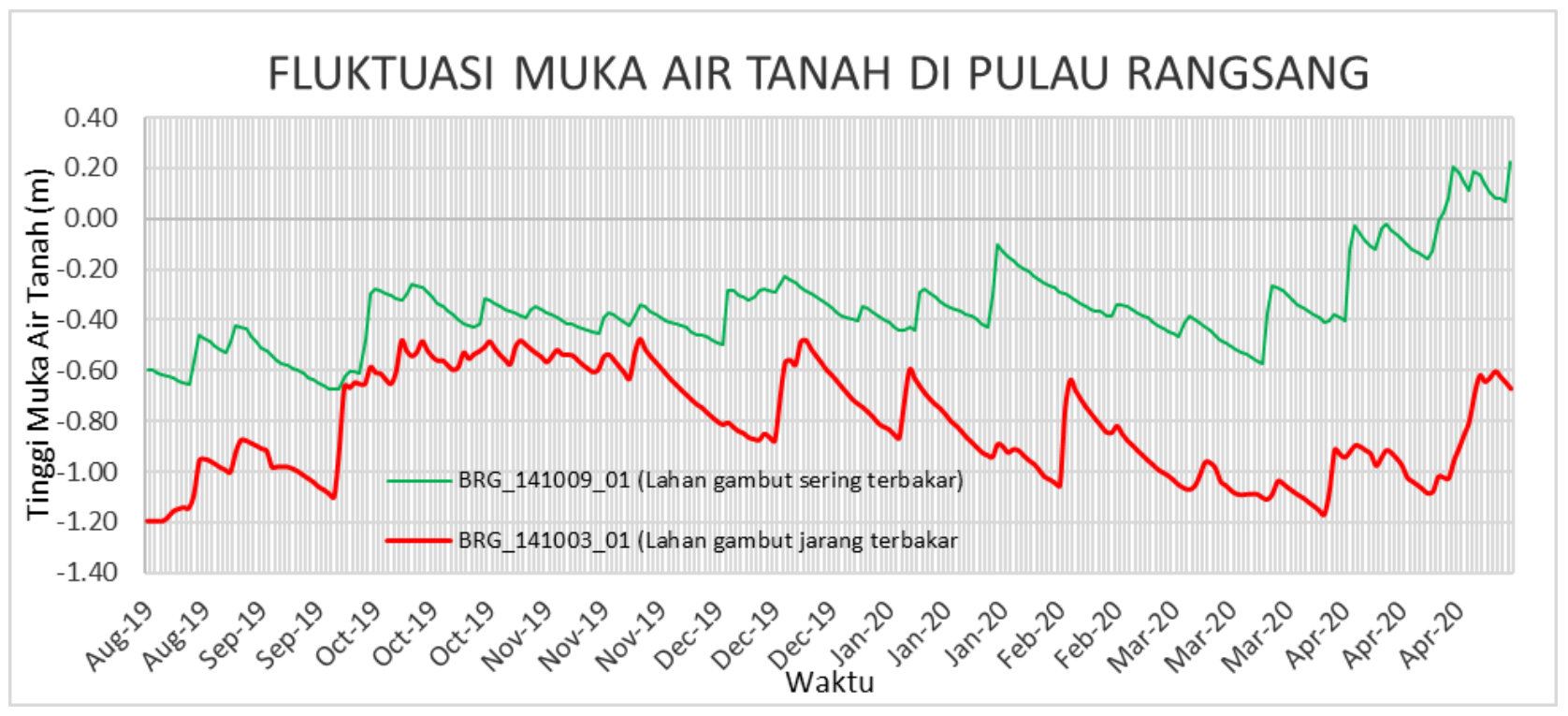

Gambar 2 Fluktuasi muka air tanah di Pulau Rangsang (Data: sipalaga.brg.co.id) 


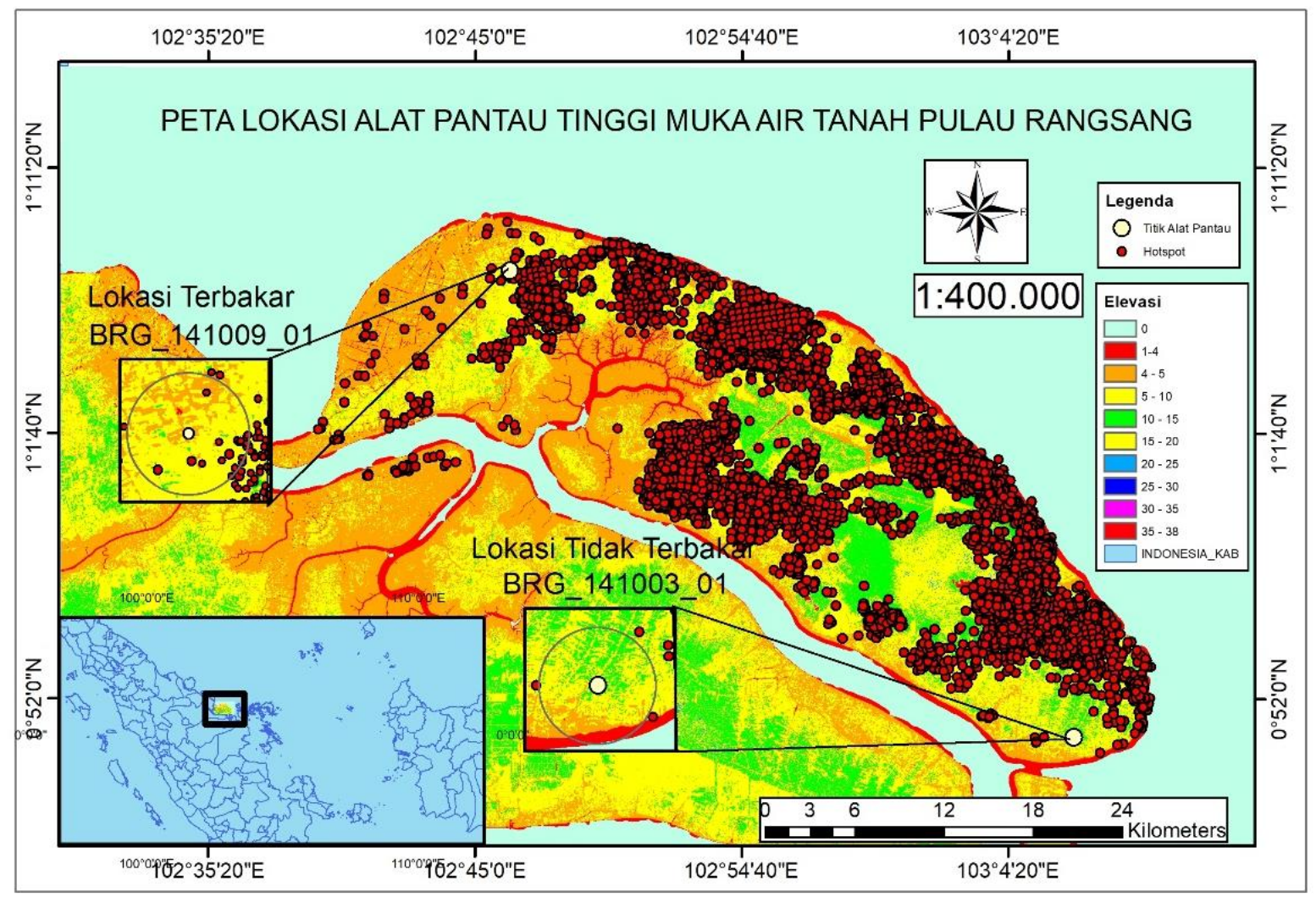

Gambar 3 Kebakaran di Pulau Rangsang dari 2009-2019 berdasarkan MODIS-VIIRS

Menurut Hendromono et al. (2007), pembukaan lahan tanpa bakar adalah konsep pengelolaan lahan gambut berkelanjutan, dimana pada tahapan pembukaan lahan hingga pasca panen tidak melakukan pembakaran sama sekali. Inovasi ini dikembangkan menjadi PLGTB dengan memperhatikan upaya-upaya yang secara khusus harus dilakukan di ekosistem gambut. Upaya ini tentunya akan mempertahankan gambut untuk tetap basah, bersifat mudah menyerap air (hidrofilik), tidak terjadi subsiden, dan berujung pada konservasi gambut secara holistik yang mampu menyimpan karbon dalam jumlah besar.

Di sisi lain peningkatan produktivitas tanaman tetap harus diperhatikan. Dalam rangka meningkatkan produktivitas lahan gambut di zona budidaya, penyediaakan nutrisi yang ramah gambut (tidak menyebabkan percepatan dekomposisi dan emisi gas rumah kaca) diperlukan. Aplikasi dalam upaya peningkatan produktivitas perlu inovasi dalam teknologi decomposer di lahan gambut salah satunya adalah StarTmik. StarTmik LIPI adalah dekomposer berupa jamur aerob. Isolasi dan seleksi berbasiskan aktivitas-aktivitas enzim lignin peroxidase, selulase, atau protease), yang berperan dalam proses humifikasi dari seresah lantai tanaman hutan dalam uji laboratorium. Agen decomposer ini diaplikasikan pada proses pengomposan yang terpisah dari lahan gambut, menggunakan bahan-bahan yang tersedia di sekitar, seperti serasah hasil pembersihan lahan, kotoran hewan ternak, hijauan liar yang tumbuh di sekitar lahan. Sumber utama adalah dari pembersihan gulma atau tanaman perdu dan rumput liar di jalan sekitar dan di kebun lahan gambut dengan cara dipotong, sehingga ramah lingkungan dibanding kebiasaan yang dilakukan dengan penyemprotan herbisida. Disamping meracuni tanah, penyemprotan herbisida juga akan menjadikan gulma, rumput dan perdu menjadi kering sehingga sangat rentan sebagai pemicu terjadinya kebakaran. Pembuatan kompos yang berbasis tanaman penutup tanah penambat $\mathrm{N}$ dari kelompok leguminoseae juga dapat menghasilkan kompos yang berkualitas dengan kandungan $\mathrm{N}$ yang tinggi (Gambar 4). 


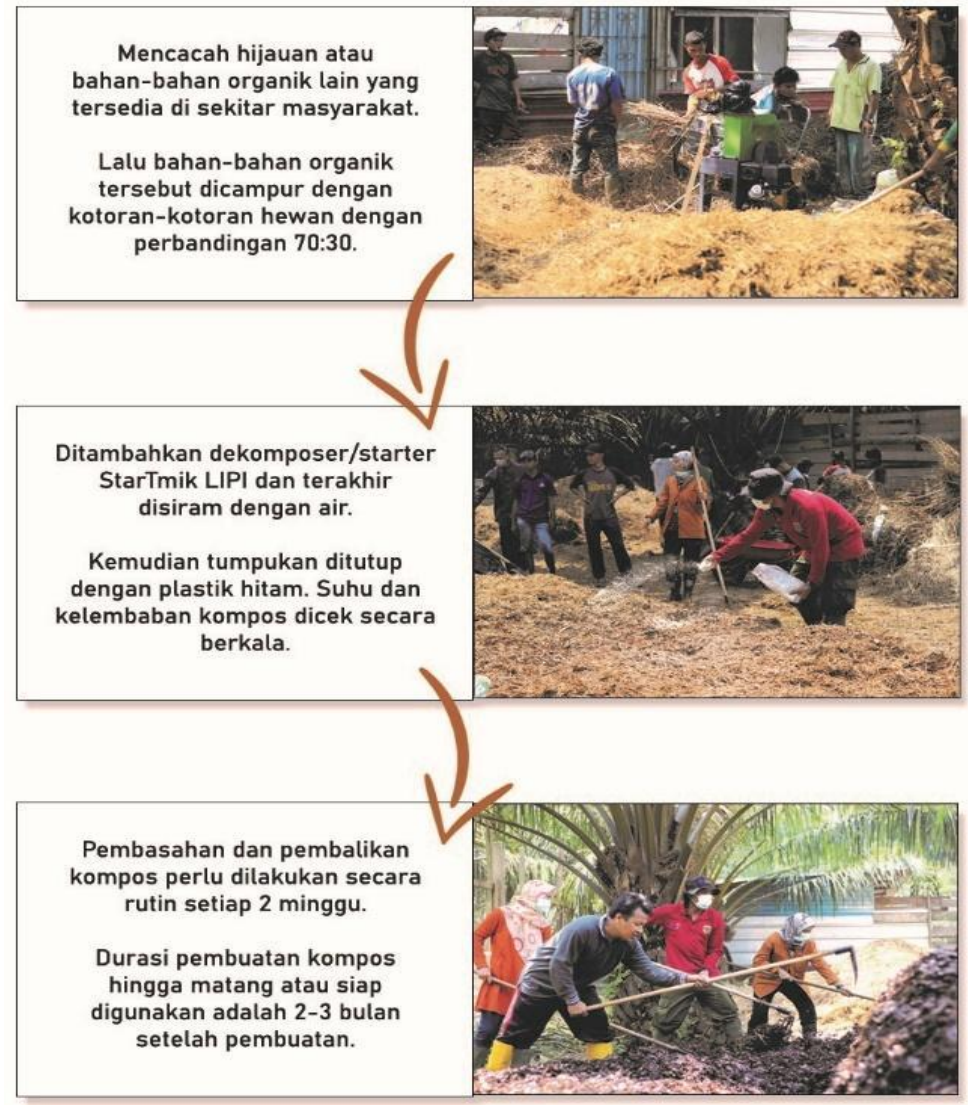

Gambar 4 Tahapan proses pembuatan kompos (Dokumentasi: LIPI dan Badan Restorasi Gambut)

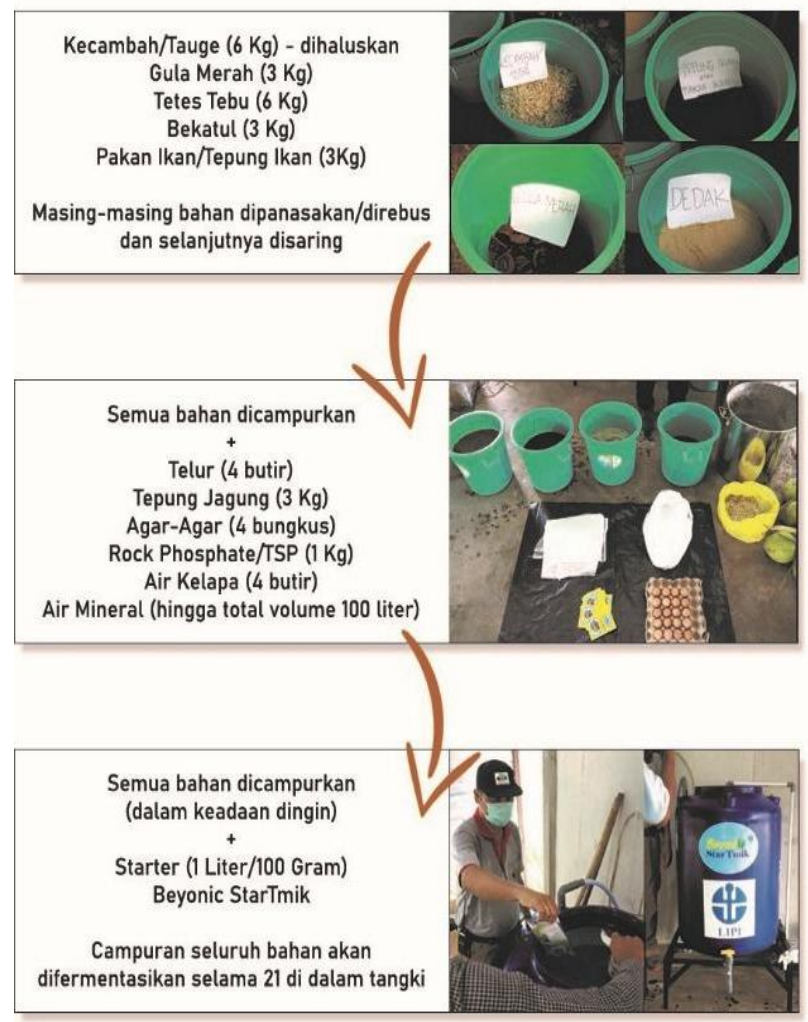

Gambar 5 Tahapan proses pembuatan POH (Dokumentasi: LIPI dan Badan Restorasi Gambut) 
LIPI dengan berbasis Plant Growth-Promoting Rhizobacteria (PGPR) telah melakukan inovasi dan mengembangkan pupuk organik hayati (POH) (Patent ID Paten No. 00064813, 2019). POH ini dinamakan Beyonic (Beyond Bio-Organic) StarTmik. Agen hayati PGPR dalam POH telah diseleksi dan dikarakterisasi aktivitas enzimatiknya sesuai dengan peruntukannya sebagai agen penyubur tanaman, biokontrol dan bioremediasi lahan (Gambar 5). Aktivitas multibiokatalis pupuk ini mampu menyediakan N, melarutkan P dan K, merombak polutan, serta menghasilkan Zat Pengatur Tubuh (ZPT), asam-asam organik, dan Biopestisida yang cocok dengan karakteristik berbagai macam jenis lahan, termasuk lahan gambut yang terkenal dengan tingkat keasamannya yang tinggi.

Prinsip inovasi POH adalah menumbuhkan bebeberapa isolat PGPR pada media tumbuh yang sangat tinggi kandungan nutrisinya seperti tepung ikan (pakan ikan) dengan kadungan sekitar 40\%, ekstrak rebusan tauge (kacambah kacang hijau), rumput laut (agar-agar), air kelapa muda, bekatul dan molase/gula merah dan selanjutkan difermentasikan secara aerob penuh dengan otomatis pengadukan dan suplai oksigen dengan mesin aerator (Antonius dan Agustiyani, 2016; Antonius et al., 2016). Dengan teknologi inovasi tersebut maka sel PGPR akan tumbuh menjadi sekitar 108 pembentuk koloni (CFU) dan menghasilkan ZPT dan metabolitmetabolit penting bagi pertumbuhan dan mengatasi stres tanaman seperti pada lahan gambut yang sengaja dijaga air muka yang tinggi.

Penelitian ini menunjukkan bahwa adanya urgensi mencegah kebakaran menuju penataan kembali ekosistem gambut berbasiskan neraca air dengan meminimalkan kehilangan fungsi fisik lahan gambut dalam memegang air. Pada bagian 3.1 diperoleh bahwa lahan gambut yang sering terbakar memiliki TMA yang lebih rendah, dan semakin rentan terhadap kebakaran berikutnya. Hal ini dapat dilihat dari hasil pengamatan gambut kepulauan seperti di Pulau Rangsang. Diperlukan pencegahan kebakaran gambut dalam upaya restorasi ekosistem gambut, dan dalam hal ini aspek hidrologi adalah aspek kunci. Lahan gambut yang sudah terbakar dan sering terbakar cenderung semakin rentan. Hal ini dapat disebabkan oleh laju degradasi lahan gambut dipercepat dengan perubahan lahan (tutupan dan drainase) dan perubahan iklim (Dohong et al., 2017). Drainase menyebabkan feedback loop yang positif, yaitu menyebabkan dampak kerusakan semakin tinggi intensitasnya. Dalam hal ini, drainase menyebabkan rentannya lahan gambut terhadap kebakaran, dan kedua kejadian ini semakin mengurangi ketersediaan air tanah, sehingga air tanah dalam komponen neraca air semakin defisit (Thompson et al., 2014). Lahan gambut yang sudah terbakar cenderung memiliki kemampuan menahan air yang lebih rendah daripada lahan gambut yang tidak terbakar. Sehingga hujan mudah terlepas (discharge) dengan limpasan (stream flow) yang semakin tinggi (Neary et al., 2005).

Sementara itu, terbakarnya vegetasi dan pepohonan mengurangi kelembapan tanah dengan berkurangnya transpirasi dan intersepsi (Van Seters dan Price, 2001; Simorangkir, 2006). Sehingga, kebakaran lahan gambut dan vegetasi di atasnya menyebabkan keseimbangan air (water balance) menjadi berada pada kondisi tingginya out flow. Vegetasi mempengaruhi keseluruhan hidrologi untuk lahan gambut, karena lahan yang terbuka menyebabkan evaporasi dan evapotranspirasi lebih tinggi serta menguras tampungan air. Vegetasi yang rusak tersebar di wilayah kebakaran. Bekas kebakaran tersebut jarang ditumbuhi kembali anakan pohon, pakis dan tanaman merambat (Ballhorn et al., 2009). Dalam penelitian di Kalimantan tengah menunjukkan dampak kebakaran terhadap kerusakan kanopi hutan serta serasah mengering rentan terhadap kebakaran (Page et al., 2019).

Secara umum, prinsip restorasi gambut adalah pembasahan serta terjaganya kelembapan (Tapio-Biström et al., 2012). Pada saat muka air turun terjadi oksidasi, gambut akan mengalami dekomposisi (Dommain et al., 2010), dan dapat berpotensi terjadi kebakaran. Kebakaran terhenti apabila turun hujan dan muka air tanah kembali naik (Page dan Hooijer, 2016). Muka air dijaga tidak lebih rendah dari $-40 \mathrm{~cm}$ agar tidak terjadi kebakaran (Putra, 2011). Perlu dibangun sekat kanal pada kanal yang menguras tampungan air (Ritzema et al., 2014). Disisi lain pengelolaan air harus dapat menyediakan kebutuhan air yang optimal untuk tanaman dan restorasi gambut (Wosten dan Ritzema, 1997). 
PLTGB adalah alternatif antara menuju restorasi gambut. Selain pembersihan lahan dalam persiapan lahan untuk pertanian, pembakaran lahan gambut adalah praktik untuk mendapatkan unsur hara dari abu-abu pembakaran secara instan. Tanpa disadari oleh masyarakat, sebenarnya proses hidrologi mencuci unsur hara dari abu-abu tersebut secara cepat apalagi pada lahan yang sudah mengalami kebakaran yang berulang karena limpasan permukaan lebih cepat, infiltrasi dan perkolasi tanah gambut. Hal ini disebabkan oleh gambut yang kering dan sudah mengalami tebakar menurun kemampuannya dalam menahan air.

Urgensi pemanfaatan gambut berbasiskan gambut basah dan tanpa bakar penting untuk mencegah rusaknya ekosistem gambut. Pertanian di lahan gambut terdegradasi yang sudah terlanjur perlu meminimalkan dampak negatif kerusakan lingkungan (Surahman et al., 2018). Pemanfaatan tersebut perlu memastikan bahwa lahan gambut yang tersisa masih memiliki kawasan yang penting untuk melindungi lingkungan untuk generasi sekarang dan masa depan (Joosten dan Clarke, 2002). Rusaknya ekosistem gambut ditandai dengan subsidensi dan hilangnya lapisan lahan gambut akibat muka air tanah (MAT) yang turun drastis (Silvius dan Suryadiputra, 2005). Selanjutnya, permukaan lahan berada pada elevasi yang tidak memungkinkan aliran air dari daerah kubah (lebih tinggi) ke kaki kubah, sehingga lahan tidak dapat di drainase (undrainabilitiy) (Ritzema, 2001). Rusaknya ekosistem gambut akan semakin dipercepat dengan pembukaan lahan dengan cara membakar. Jika gambut habis terbakar dan hanya tersisa lapisan di bawahnya, maka hamparan yang terbentuk tidak akan dapat dipulihkan kembali (Pinem, 2016).

Kompos yang diberikan adalah alternatif sumber hara yang baiknya diaplikasikan pada musim hujan karena kondisi anaerob dapat tercipta. Fluktuasi muka air di lahan gambut tropis sangat bergantung pada curah hujan. Dalam beberapa bulan periode musim hujan, kondisi akar cenderung anaerob karena terendam air, sedangkan selama musim kemarau dihadapkan dengan fisiologis defisit air. Sehingga musim kemarau tidak disarankan untuk diaplikasikannya kompos ini. Musim kemarau pada berbagai KHG berbeda, terutama KHG kepulauan yang mengalami dua kali musim kemarau dalam setahun. Pengecualian pada hal ini adalah pada daerah-daerah yang stabil TMA di atas $-40 \mathrm{~cm}$ sepanjang tahun, yang mana masih sulit dicapai kestabilan ini kecuali dengan penataan zona air yang spesifik, .sehingga diperlukan penentuan dan perencanaan zona air untuk pembangunan lahan pertanian pada fungsi gambut budidaya. Hal tersebut agar memastikan ketercukupan air selama proses produksi dengan tetap memprioritaskan tujuan restorasi gambut.

PLGTB memberikan implikasi secara hidrologi dan sosial. Lahan gambut, vegetasi dan air memiliki keterkaitan dan saling membutuhkan (Page et al., 1999), PLGTB memberikan implikasi secara hidrologi dan sosial. Secara hidrologi, PLTGB memberikan waktu pembenahan dalam penataan hidrologi gambut dengan rewetting dan revegetasi. Secara sosial, dalam kompleksitas sosial dalam merestorasi gambut diperlukan pendekatan sosial yang khas dan unik, berbeda dengan upaya restorasi gambut di Eropa misalnya. BRG menyelenggarakan sekolah lapang untuk melatih petani membuka lahan tanpa bakar. Hal ini diperlukan masyarakat untuk beradaptasi pada kebijakan larangan membakar lahan. Diharapkan dengan adanya keterikatan masyarakat dengan lahannya ini dan alternatif yang mencegah pengelolaan lahan dengan membakar memberikan ruang bagi pengertian masyarakat akan pentingnya restorasi gambut, dan mengurangi konflik kepentingan. Selain itu, pembinaan dan pengawasan petani harus terus dilakukan (Herman, 2015). Mahalnya proses pembukaan lahan jika tidak dilakukan dengan membakar perlu dicarikan solusi kepada petani untuk menaikkan produktivitas lahan agar menutupi biaya di awal bertani. Berbagai jenis teknologi tanah dan air yang sesuai tersedia untuk meningkatkan kesuburan dan pemeliharaan ketinggian air tanah. Ini termasuk pengelolaan air makro dan mikro, perbaikan, pemupukan, varietas tanaman adaptif, pengelolaan hama terpadu dan mekanisasi pertanian (Suriadikarta, 2009).

Dalam penelitian ini terdapat keterbatasan dalam kajiannya dan merupakan implikasi dalam langkah selanjutnya. Keseimbangan air penting untuk restorasi dan menata fungsi budidaya. Data neraca air di suatu wilayah selama periode tertentu diperlukan (Moghadas, 2009). Tata Kelola air di lahan gambut perlu meninjau pemodelan neraca air untuk perencanaan pembukaan lahan. Dalam beberapa penelitian digunakan aplikasi MODFLOW (Ishii et al., 2016; Rossi et al., 2014) dan SIMGRO (Wosten et al., 2006) untuk menghitung komponen neraca air. PLTGB perlu memperhatikan tata kelola air untuk proses rewetting dan juga 
pertumbuhan tanaman. Pada gambut yang telah terdegradasi akibat kanal maka dilakukan pemetaan dan perhitungan air yang keluar dari sistem akibat kanal. Pembangunan sekat kanal diperlukan untuk rewetting (Jaenicke et al., 2010), sekaligus memberikan kebutuhan tanaman dan pencegahan kebakaran. Tata Kelola air berbeda tergantung fungsi dari lahan tersebut termasuk perkebunan di lahan gambut (Wosten et al., 2008). Hubungan antara tinggi muka air dan kebutuhan optimal produktivitas tanaman direncanakan untuk jangka waktu tahunan. Tujuan restorasi di lahan gambut menjadi tujuan utama dengan optimalisasi produktivitas pertanian, maka dikenal konsep paludikultur. Pembukaan lahan tanpa bakar dapat dilakukan untuk mendukung konsep tersebut.

\section{SIMPULAN}

Degradasi ekosistem gambut perlu dicegah dengan penataan kembali ekosistem gambut. Penataan kembali ekosistem gambut tropis memerlukan alternatif antara dalam mencapai terestorasinya gambut secara permanen. PLGTB merupakan salah satu alternatif antara tersebut, karena trade-off kebutuhan masyarakat untuk mengelola lahan diperlukan. Integrasi dengan tujuan restorasi gambut adalah mempertemukan kebutuhan masyarakat tersebut dengan praktik yang menstimulasi gambut tetap basah. Penggunaan ameliorant seperti kompos dan agen hayati dapat dilakukan pada kondisi gambut basah saja (pada musim hujan atau pada area yang lembab stabil sepanjang tahun). Pada saat gambut basah, kompos yang sudah matang dapat diaplikasikan, dan ini dapat mencegah mikroba aerob untuk aktif mendekomposisi, Tujuan menjaga gambut basah dapat dilakukan sementara unsur hara dapat disediakan.

\section{DAFTAR PUSTAKA}

[BBSDLP] Balai Besar Penelitian dan Pengembangan Sumberdaya Lahan Pertanian. 2011. Peta Lahan Gambut Indonesia Skala 1:250.000. Bogor (ID): Badan Pertanian dan Pengembangan Pertanian.

Akbar A. 2015. Studi kearifan lokal penggunaan api persiapan lahan: Studi kasus di Hutan Mawas, Kalimantan Tengah. Jurnal Penelitian Sosial dan Ekonomi Kehutanan. 8(3): 211-223.

Antonius S, Agustiyani D, Lailii N, Hartati I, Sutisna E. 2019. Pupuk Organik Hayati Cair dan Proses Pembuatannya. Paten Indonesia. ID Patent IDP 000064813.

Antonius S, Agustiyani D. 2016. Pengaruh pupuk organik hayati yang mengandung mikroba bermanfaat terhadap pertumbuhan dan hasil panen tanaman semangka serta sifat biokimia tanahnya pada percobaan lapangan. Jurnal Berkala Penelitian Hayati. 16: 203-206.

Antonius S, Budisatria R, Dewi TK. 2016. The use of sprout as precursor for the production of indole acetic acid by selected plant growth promoting rhizobacteria grown in the fermentor. Microbiology Indonesia. 10(4): 131-138.

Anwar A, Juneng L, Othman MR, Latif MT. 2010. Correlation between hotspots and air quality in Pekanbaru, Riau, Indonesia in 2006-2007. Sains Malays. 39: 169-174.

Ballhorn U, Siegert F, Mason M, Limin S. 2009. Derivation of burn scar depths and estimation of carbon emissions with LIDAR in Indonesian peatlands. Proc Natl Acad Sci. 106(50): 21213-21218. doi: https://doi.org/10.1073/pnas.0906457106.

Cole LES, Bhagwat SA, Willis KJ. 2015. Long-term disturbance dynamics and resilience of tropical peat swamp forest. J Ecol. 103(1): 16-30.

Dohong A, Aziz AA, Dargusch P. 2017. A review of the drivers of tropical peatland degradation in South-East Asia. Land Use Policy. 69: 349-360. doi: https://doi.org/10.1016/j.landusepol.2017.09.035.

Dommain R, Couwenberg J, Joosten H. 2010. Hydrological self-regulation of domed tropical peatlands. Mires and Peat. 6: 1-17. 
Harrison ME, Capilla BR, Thornton SA, Cattau ME, Page SE. 2016. Impacts of the 2015 fire season on peatswamp forest biodiversity in Indonesian Borneo. Di dalam: Salo H, Warnecke S, editor. Peatlands in harmony-Agriculture, Industry \& Nature Proceedings of the 15th International Peat Congress 2016; 2016 August 15-19; Sarawak, Malaysia. Sarawak (MY): International Peat Society. hlm 713-717.

Harrison ME, Ottay JB, D’Arcy LJ, Cheyne SM, Anggodo, Belcher C, Cole L, Dohong A, Ermiasi Y, Feldpausch, et al. 2019. Tropical forest and peatland conservation in Indonesia: Challenges and directions. People and Nature. 1-25. doi: https://doi.org/10.1002/pan3.10060.

Hendromono, Wibowo A, Martono D, Santoso E, Djarwanto, Prahasto H, Sallata MK, Rufi'ie, Suharyanto, Siran SA, Heriansyah. 2007. Penyiapan Lahan Tanpa Bakar untuk Penanaman. Jakarta (ID): Departemen Kehutanan Badan Penelitian dan Pengembangan Kehutanan.

Herman. 2015. Analysis of the farming system performance and the opportunity cost of $\mathrm{CO}_{2}$ emissions on peat farming system in Kubu Raya District, West Kalimantan. Di dalam: Suradisastra K, Hutabarat B, Swastika DKS, editor. Proceeding National Seminar 'Farmers Agriculture Development [Internet]. [diunduh 2020 Aug 16]. Tersedia pada: http://pse.litbang.pertanian.go.id/ind/pdffiles/Pros_2012_05A_ MP_Herman.pdf.

Hooijer A, Page S, Jauhiainen J, Lee WA, Lu XX, Idris A, Anshari G. 2012. Subsidence and carbon loss in drained tropical peatlands. Biogeosciences. 9: 1053-1071. doi: https://doi.org/10.5194/bg-9-1053-2012.

Ishii Y, Koizumi K, Fukami H, Yamamoto K, Takahashi H, Limin SH, Kusin K, Usup A, Susilo GE. 2016. Groundwater in peatland. Di dalam: Osaki M, Tsuji N, editor. Tropical Peatland Ecosystems. Tokyo (JP): Springer Japan. hlm 265-279.

Jaenicke J, Wosten H, Budiman A, Siegert F. 2010. Planning hydrological restoration of peatlands in Indonesia to mitigate carbon dioxide emissions. Mitig Adapt Strateg Glob Change. 15: 223-239. doi: https://doi.org/10.1007/s11027-010-9214-5

Joosten H, Clarke D. 2002. Wise Use of Mires and Peatlands-Background and Principles including a Framework for Decision-Making. Saarijärvi (FI): International Mire Conservation Group and International Peat Society.

Liu J, Bowman KW, Schimel DS, Parazoo NC, Jiang Z, Lee M, Bloom AA, Wunch D, Frankenberg C, Sun Y, et al. 2017. Contrasting carbon cycle responses of the tropical continents to the 2015-2016 El Niño. Science. 358: 1-7. doi: https://doi.org/10.1126/science.aam5690.

Maulana SI, Syaufina L, Prasetyo LB, Aidi MN. 2019. Pola tutupan, penggunaan, serta tantangan kebijakan perlindungan ekosistem gambut di Kabupaten Bengkalis. Jurnal Pengelolaan Sumberdaya Lingkungan. 9(3): 549-565. doi: https://doi.org/10.29244/jps1.9.3.549-565.

Moghadas S. 2009. Long-term water balance of an inland River Basin in an Arid Area, North-Western China [tesis]. Lund (SE): Lund University.

Neary DG, Ryan KC, Debano LF. 2005. Wildland Fire in Ecosystems: Effects of Fire on Soils and Water. Ogden (US): Rocky Mountain Research Station.

Page SE, Hooijer A. 2016. In the line of fire: the Peatlands of Southeast Asia. Phil Trans R Soc B. 371: 1-9. doi: 10.1098/rstb. 2015.0176.

Page SE, Rieley JO, Shotyk OW, Weiss D. 1999. Interdependence of peat and vegetation in a tropical peat swamp forest. Phil Trans $R$ Soc B. 354: 1885-1897.

Page S, Hoscilo A, Langner A, Tansey K, Siegert F, Limin S, Rieley J. 2019. Tropical Peatland Fires in Southeast Asia. Chichester (UK): Praxis Publishing. hlm 263-287.

Pinem T. 2016. Kebakaran hutan dan lahan gambut. Jurnal Gema Teologika. 1(2): 61-68.

Posa MRC, Wijedasa LS, Corlett RT. 2011. Biodiversity and conservation of tropical peat swamp forests. BioScience. 61: 49-57. doi: https://doi.org/10.1525/bio.2011.61.1.10.

Purnomo H, Puspitaloka D. 2020. Pembelajaran Pencegahan Kebakaran dan Restorasi Gambut Berbasis Masyarakat. Bogor (ID): CIFOR. 
Putra EI. 2011. The effect of the precipitation pattern of the dry season on peat fire occurrence in the mega rice project area, Central Kalimantan, Indonesia. Tropics. 19(4): 145-156.

Rezainy A, Syaufina L, Sitanggang IS. 2020. Pemetaan daerah rawan kebakaran di lahan gambut berdasarkan pola sekuens titik panas Di Kabupaten Pulang Pisau Kalimantan Tengah. Jurnal Pengelolaan Sumber Daya Alam dan Lingkungan. 10(1): 66-76. doi: http://dx.doi.org/10.29244/jpsl.10.1.66-76.

Ritzema.H. 2001. Water Management Guidelines for Agricultural Development in Lowland Peat Swamps of Sarawak. Sarawak, Malaysia.

Ritzema HP, Limin S, Kusin K, Jauhiainen J, Wösten H. 2014. Canal blocking strategies for hydrological restoration of degraded tropical peatlands in Central Kalimantan, Indonesia. CATENA. 114: 11-20.

Rossi PM, Ala-aho P, Doherty J, Kløve B. 2014. Impact of peatland drainage and restoration on esker groundwater resources: Modeling future scenarios for management. Hydrogeol J. 22: 1131-1145. doi: https://doi.org/10.1007/s10040-014-1127-z.

Silvius M, Suryadiputra N. 2005. Review of Policies and Practices in Tropical Peat Swamp Forest Management in Indonesia. Wageningen (NL): Wetlands International.

Simorangkir D. 2006. Fire use: Is it really the cheaper land preparation method for large-scale plantations?. Mitig Adapt Strateg Glob Change. 12: 147-164. doi: https://doi.org/10.1007/s11027-006-9049-2.

Surahman A, Soni P, Shivakoti GP. 2018. Are peatland farming systems sustainable? Case study on assessing existing farming systems in the peatland of Central Kalimantan, Indonesia. J Integr Environ Sci. 15: 119. doi: https://doi.org/10.1080/1943815X.2017.1412326.

Suriadikarta DA. 2009. Pembelajaran dari kegagalan penanganan kawasan PLG sejuta hektar menuju pengelolaan lahan gambut berkelanjutan [learning from the failure of mega rice project towards sustainable peatland management]. Pengemb Inov Pertan Agric Dev Innov J. 2(4): 229-249.

Tapio-Biström ML, Joosten H, Tol S. 2012. Peatlands: Guidance for Climate Change Mitigation through Conservation, Rehabilitation and Sustainable Use. $2^{\text {nd }}$ ed. Rome (RO): Food and Agriculture Organization of the United Nations and Wetlands International.

Thompson DK, Benscoter BW, Waddington JM. 2014. Water balance of a burned and unburned forested boreal peatland: Water balance of boreal peatlands subject to wildfire. Hydrol Process. 28: 5954-5964. doi: https://doi.org/10.1002/hyp.10074.

Thornton SA, Dudin, Page SE, Upton C, Harrison ME. 2018. Peatland fish of Sebangau, Borneo: Diversity, monitoring and conservation. Mires and Peat. 22(4): 1-25.

Van Seters TE, Price JS. 2001. The impact of peat harvesting and natural regeneration on the water balance of an abandoned cutover bog, Quebec. Hydrol Process. 15: 233-248. doi: https://doi.org/10.1002/hyp.145.

Wosten JHM, Ritzema HP. 1997. Land and Water Management Option for Peatland Development in Sarawak, Malaysia. International Peat Journal. 11: 59-66.

Wosten H, Ritzema H, Rieley J. 2008. Requirement for and Operational Aspects of Water Management in Tropical Peatlands. Wageningen (NL): Wageningur.

Wosten H, Hooijer A, Siderius C, Rais DS, Idris A, Rieley J. 2006. Tropical peatland water management modelling of the air hitam laut catchment in Indonesia. Int J River Basin Manag. 4: 233-244. doi: https://doi.org/10.1080/15715124.2006.9635293.

Yuliani F, Saktioto S, Rosnita R, Pailis E, Murniati M, Tjarsono, I. 2019. Sistem pengolahan lahan tanpa bakar dalam kebakaran hutan dan lahan pada kawasan gambut Kecamatan Bukit Batu Kabupaten Bengkalis. Di dalam: Arifudin, Dini IS, editor. Unri Conference Series: Community Engagement. Pekanbaru (ID): Universitas Riau. hlm 645-651. doi: https://doi.org/10.31258/unricsce.1.645-651. 